CORRECTION

\title{
Correction to: The Struggling Towards a Transdisciplinary Metaphysics
}

\section{Paul Gibbs ${ }^{1,2}$ (D)}

Published online: 14 December 2021

(c) Springer Nature Switzerland AG 2021

\section{Correction to: Postdigital Science and Education https://doi.org/10.1007/s42438-021-00278-w}

The article was published with an error. The author name has been corrected to Paul Gibbs. Thus, this erratum is presented to fix this error.

The original article has been corrected.

The original article can be found online at https://doi.org/10.1007/s42438-021-00278-w.

Paul Gibbs

p.gibbs@mdx.ac.uk

1 European University, London, UK

2 Middlesex University, London, UK 